Far-red Light-activatable Prodrug of Paclitaxel for the Combined Effects of Photodynamic Therapy and Site-specific

\title{
Paclitaxel Chemotherapy
}

Pritam Thapa, Mengjie Li, Moses Bio, Pallavi Rajaputra, Gregory Nkepang, Yajing Sun, Sukyung Woo, Youngjae You*

College of Pharmacy, University of Oklahoma Health Sciences Center, Oklahoma City, OK, 73117 


\section{List of Contents}

1. Figure $\mathrm{S} 1-8 .{ }^{1} \mathrm{H}$ and ${ }^{13} \mathrm{C}$ NMR spectra of the selected compounds

2. Figure S9, S10. HRMS spectra of $\mathbf{4}$ and $\mathbf{5}$

3. Figure S11, 12. HPLC chromatograms of $\mathbf{4}$ and $\mathbf{5}$

4. Figure $\mathrm{S} 13 . \mathrm{UV} / \mathrm{Vis}$ spectra of $\mathbf{4}$ and $\mathbf{5}$ at a series of concentrations

5. Procedure for sample collection from HPLC for HRMS

6. Figure S14. HPLC chromatogram and HRMS of the purified fraction of the released product from the illuminated sample of 4

7. Tubulin polymerization effects of illuminated samples of compounds $\mathbf{4}$ and $\mathbf{5}$

8. Figure S15. Effects of $\mathbf{4}$ or $\mathbf{5}$ on tubulin polymerization at $1.5 \mu \mathrm{M}$ concentration, before and after illumination

9. Figure S16. Figure S16. Enlarged images of Figures 6aiv and 6biv.

10. Figure S17. Relative fluorescence intensity of $\mathbf{4}$ and $\mathbf{5}$ in medium or Tween $80(1 \%) /$ dextrose (5\%) 


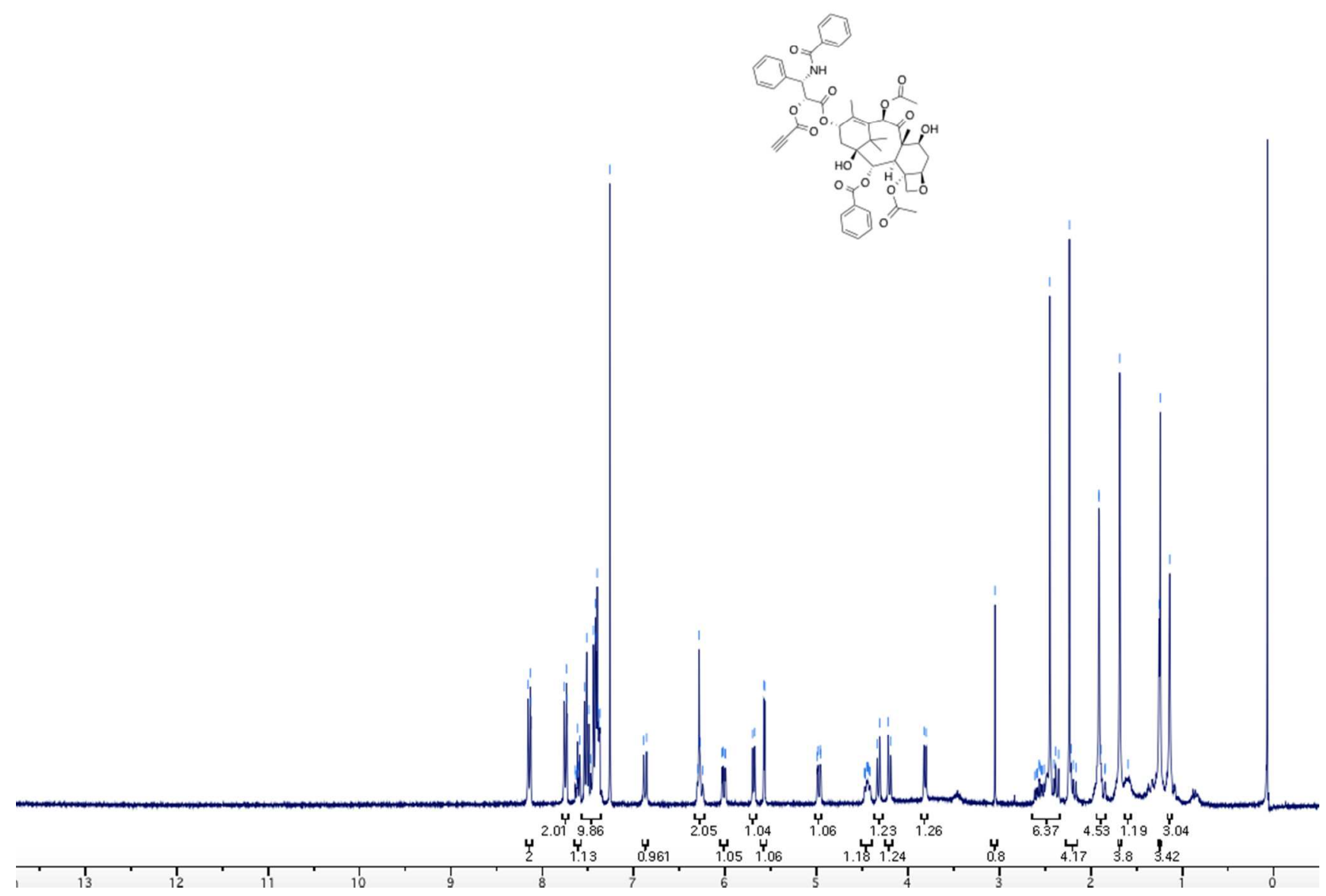

Figure S1. ${ }^{1} \mathrm{H}$ NMR spectrum of 1 in $\mathrm{CDCl}_{3}$. 


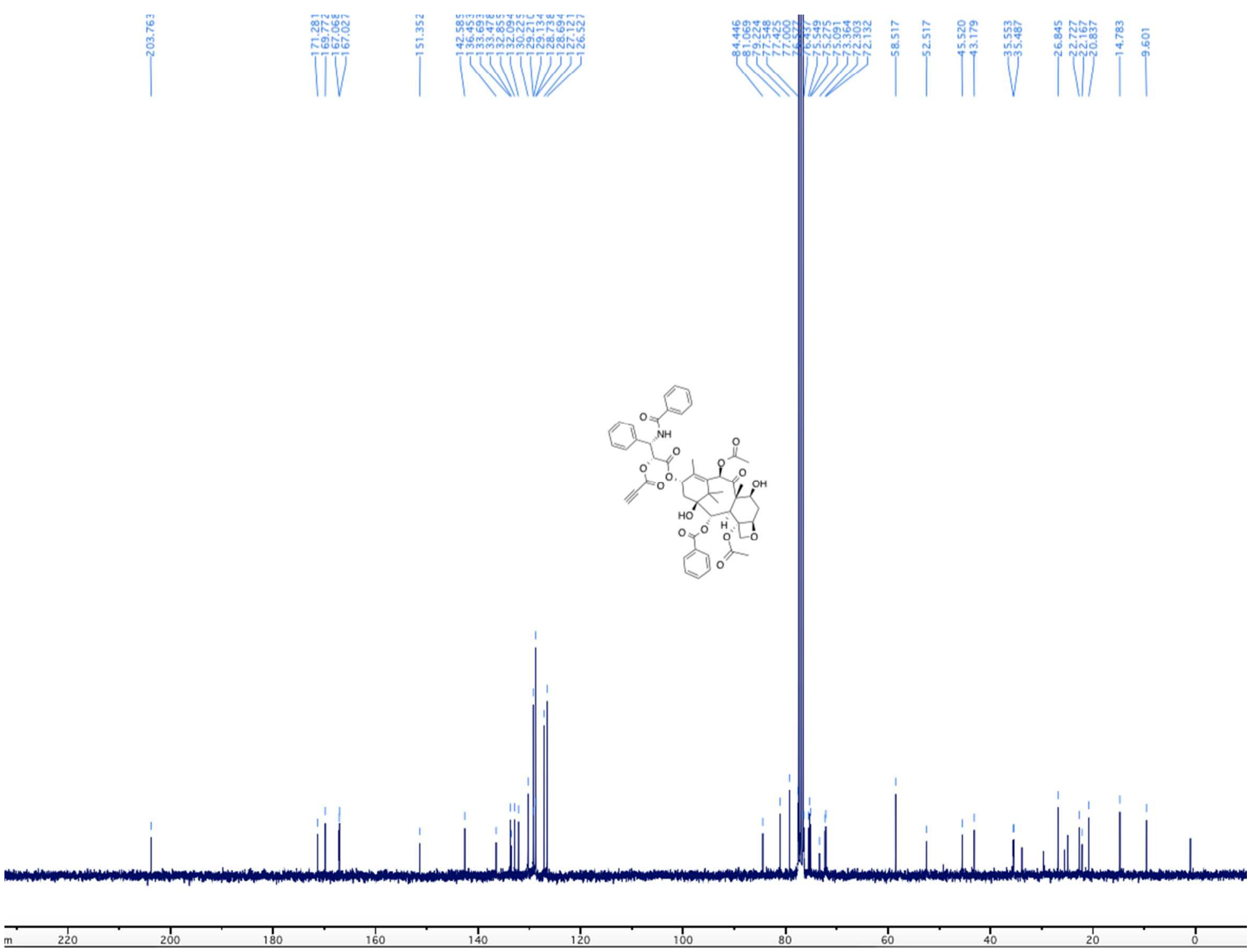

Figure S2. ${ }^{13} \mathrm{C}$ NMR spectrum of $\mathbf{1}$ in $\mathrm{CDCl}_{3}$. 


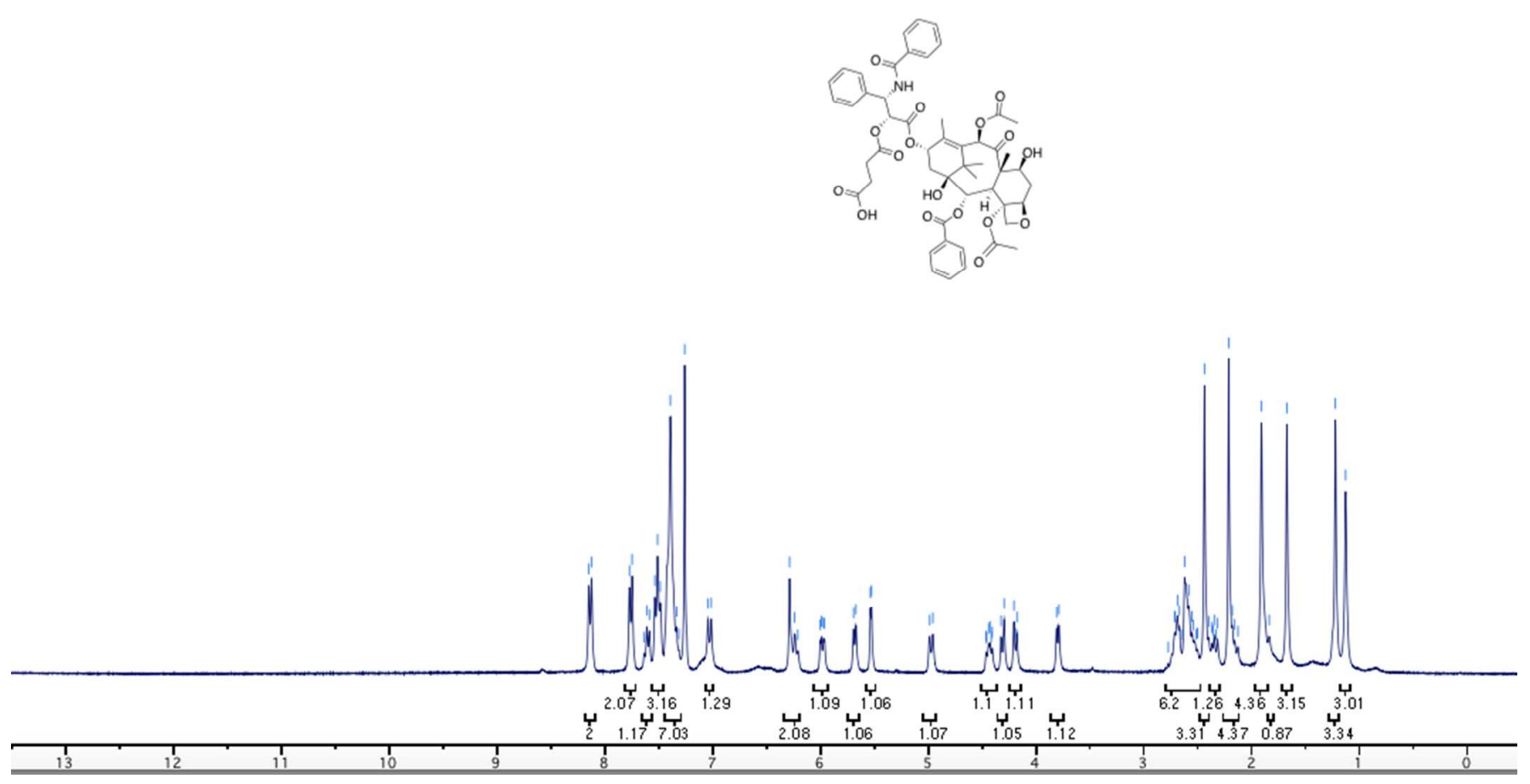

Figure S3. ${ }^{1} \mathrm{H}$ NMR spectrum of 3 in $\mathrm{CDCl}_{3}$. 


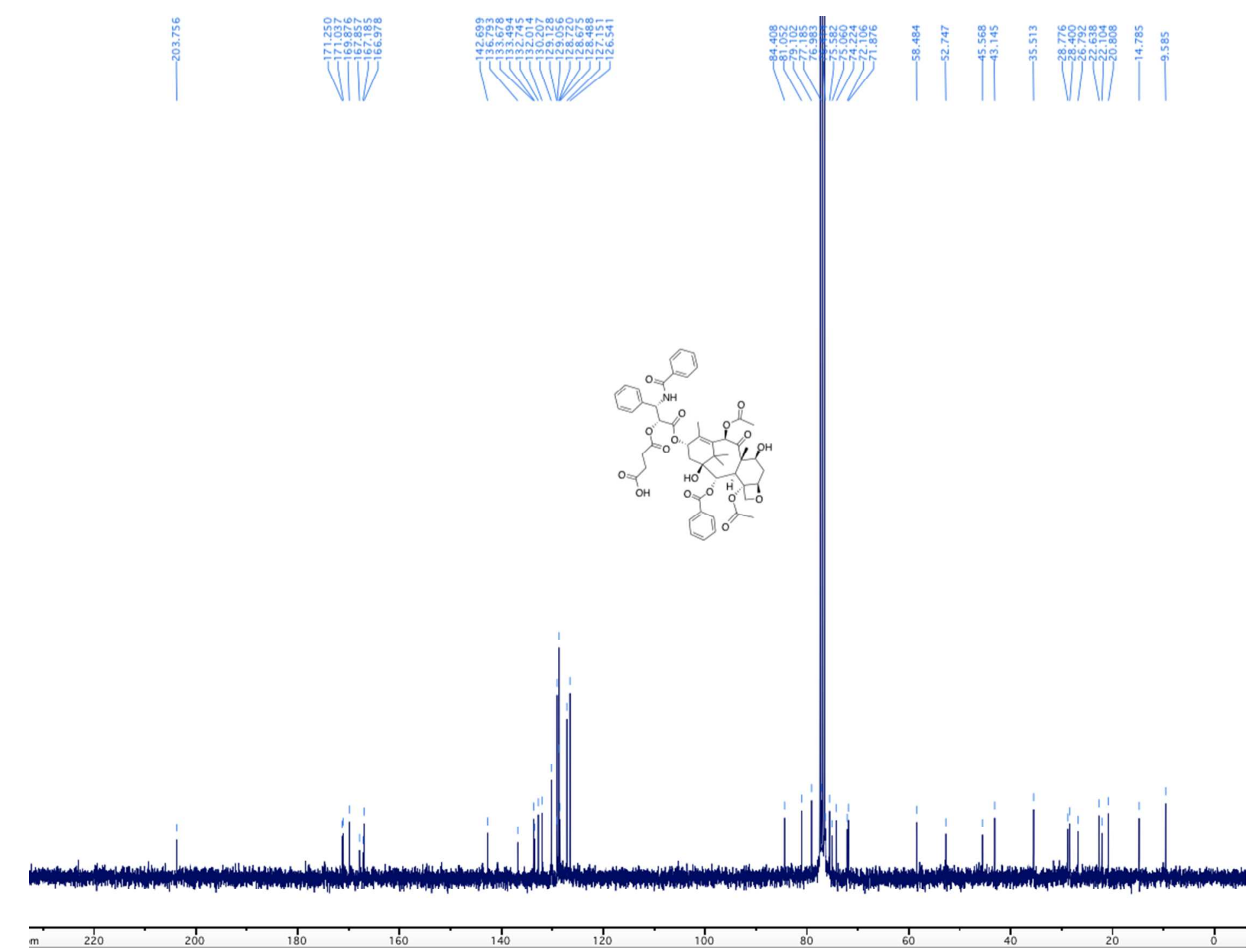

Figure S4. ${ }^{13} \mathrm{C}$ NMR spectrum of 3 in $\mathrm{CDCl}_{3}$. 


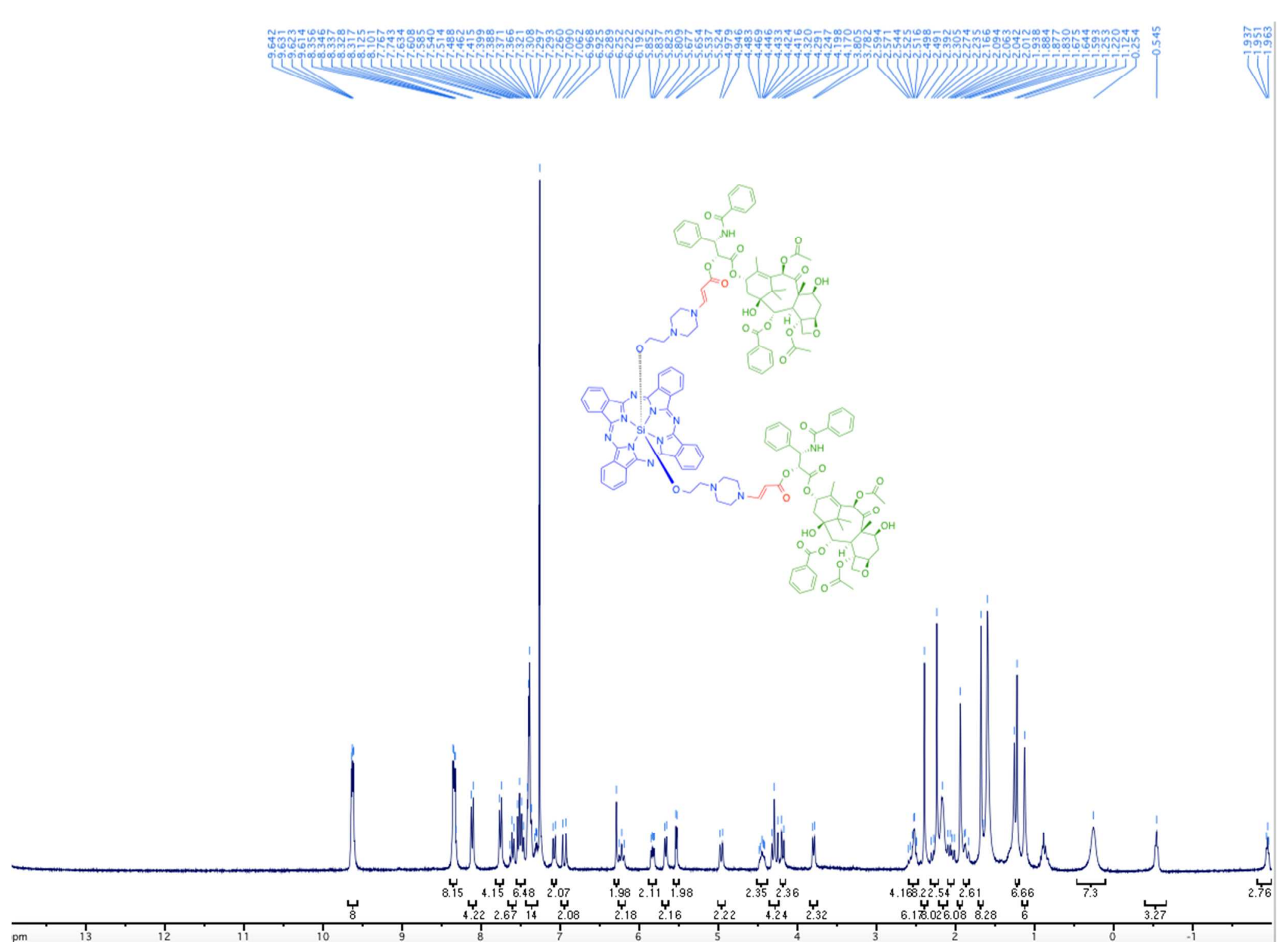

Figure S5. ${ }^{1} \mathrm{H}$ NMR spectrum of 4 in $\mathrm{CDCl}_{3}$. 


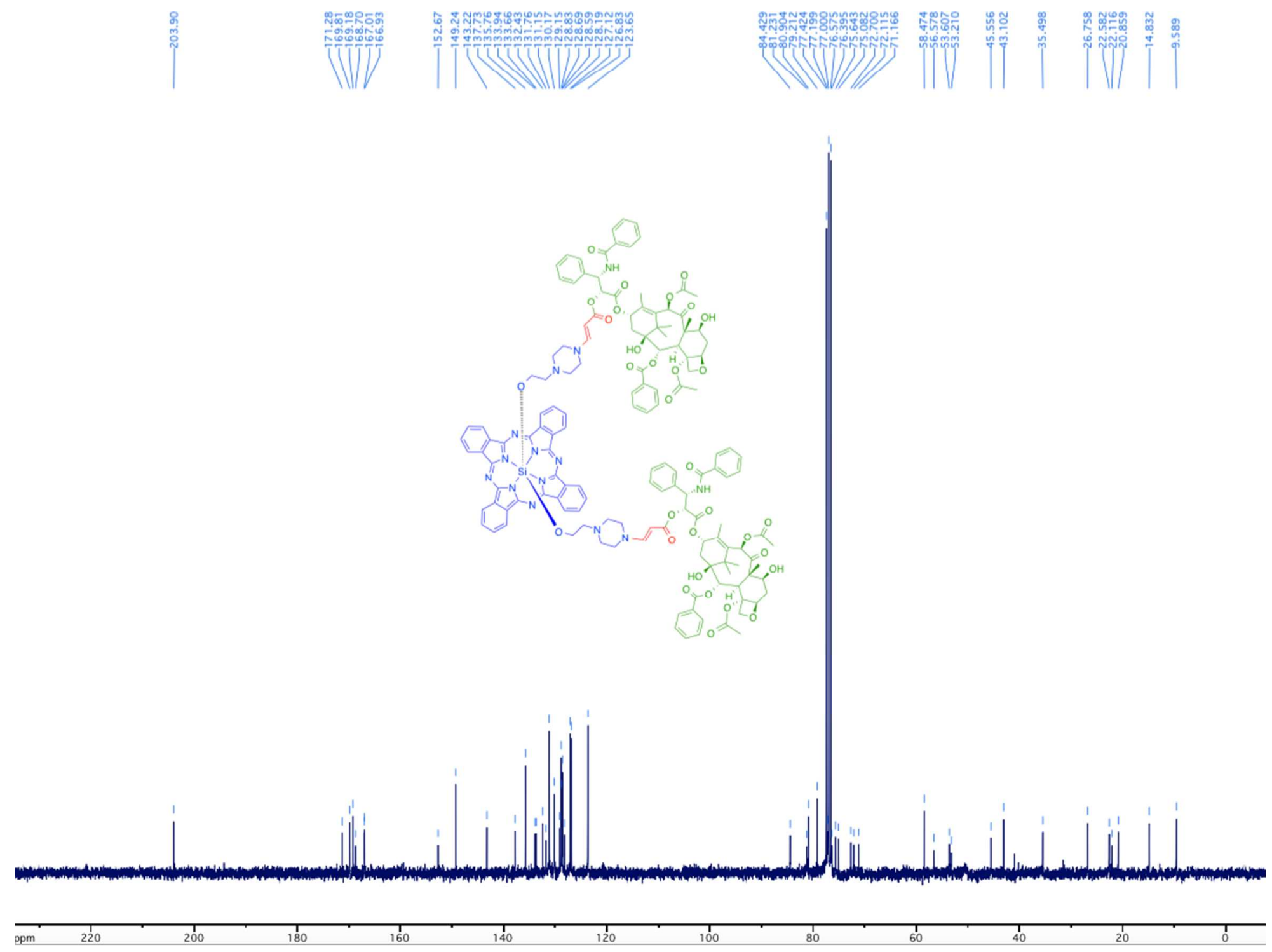

Figure S6. ${ }^{13} \mathrm{C}$ NMR spectrum of 4 in $\mathrm{CDCl}_{3}$. 


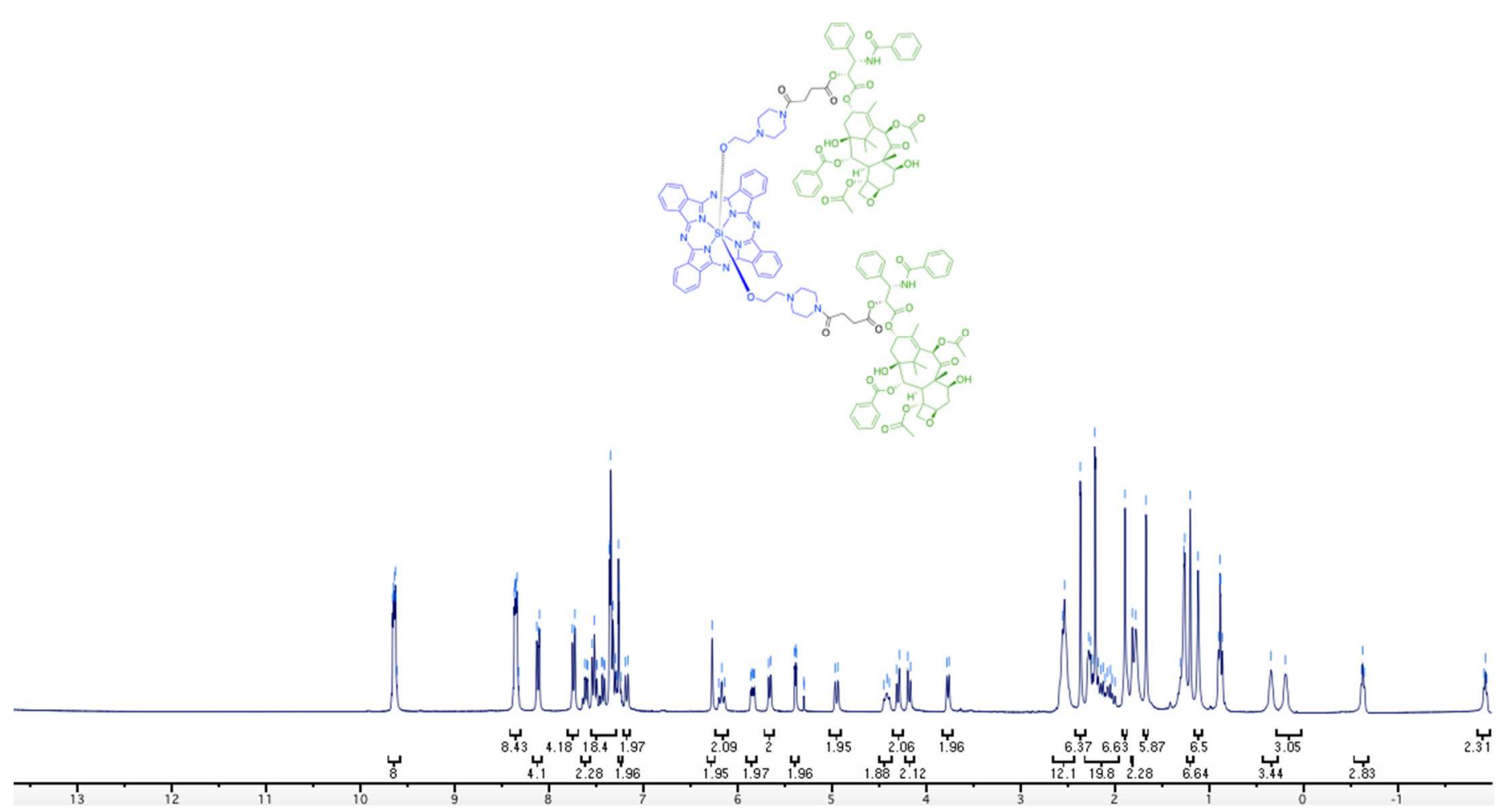

Figure S7. ${ }^{1} \mathrm{H}$ NMR spectrum of 5 in $\mathrm{CDCl}_{3}$. 

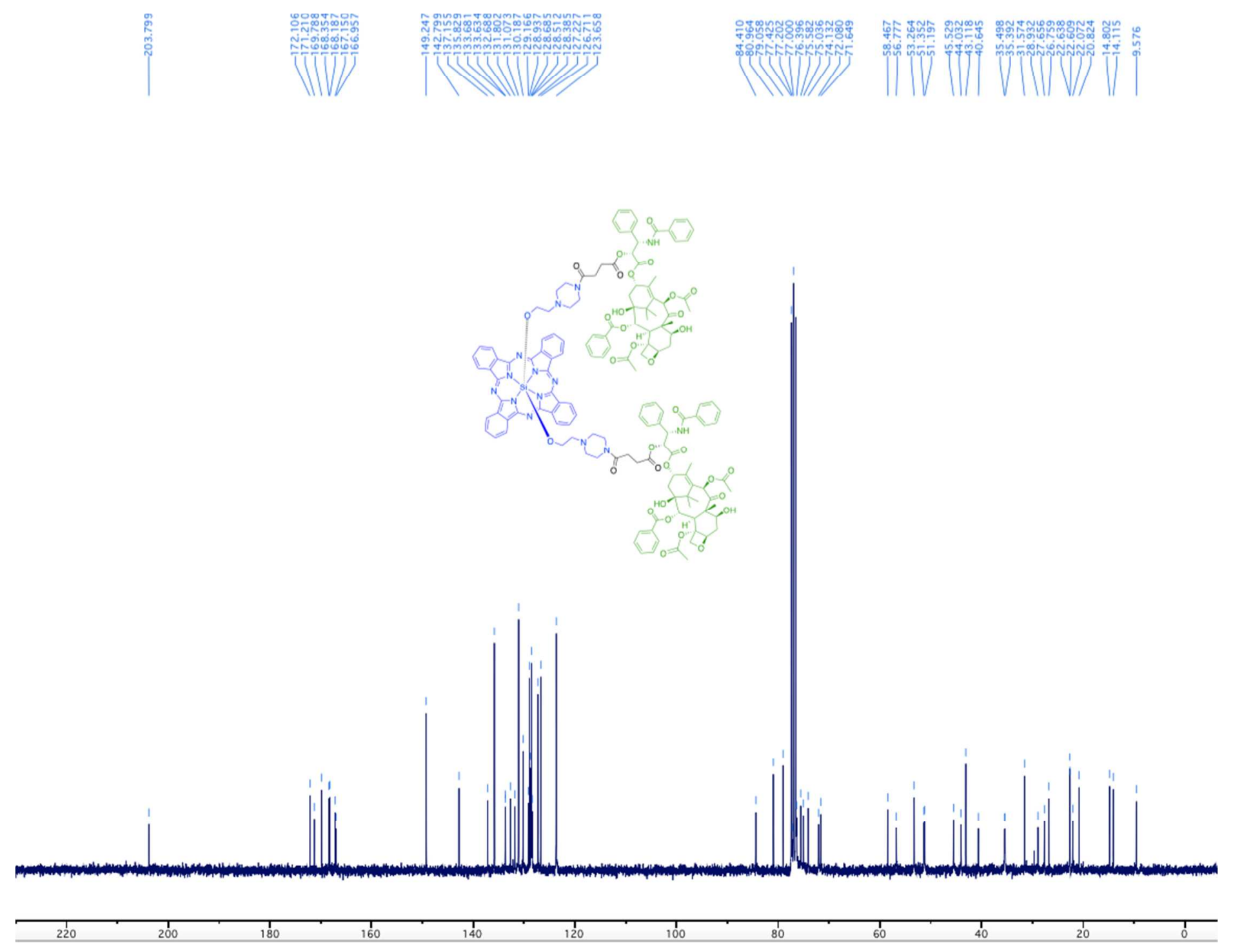

Figure S8. ${ }^{13} \mathrm{C}$ NMR spectrum of 5 in $\mathrm{CDCl}_{3}$. 
+TOF MS: 69 MCA scans from Sample 1 (PT-I-67) of 20150423A You-1673 PT-I-67 MCA.wiff

Max. 6.9e4 counts.

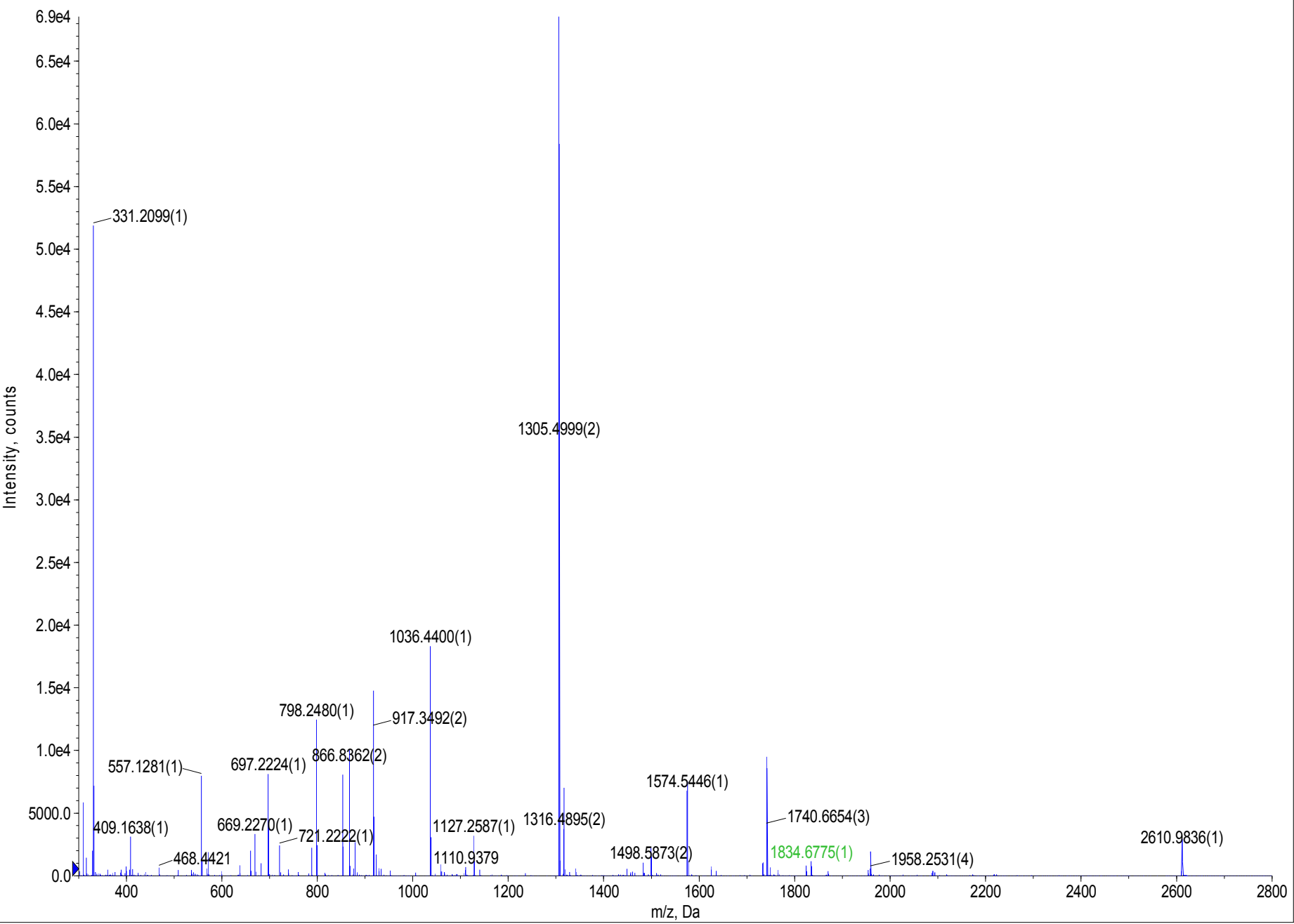

Figure S9. HRMS spectra of prodrug 4 . 
+TOF MS: 84 MCA scans from Sample 1 (TuneSamplelD) of 2015-0826 You-2448 PT-I-127.wiff

$\mathrm{a}=3.59727356548183780 \mathrm{e}-004, \mathrm{t} 0=-8.38306272445190360 \mathrm{e}+000$ (Nanospray)

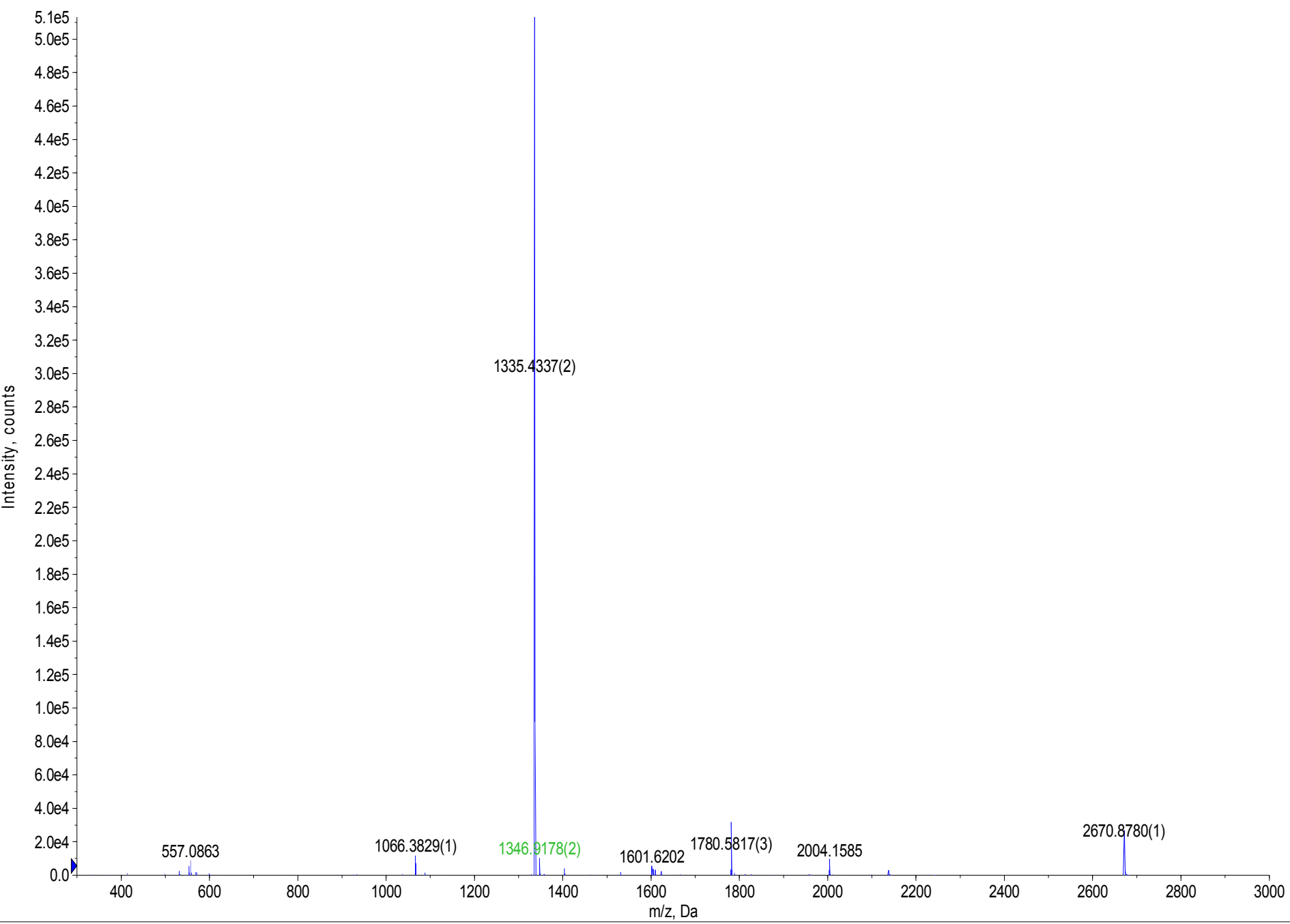

Figure S10. HRMS spectra of prodrug 5. 


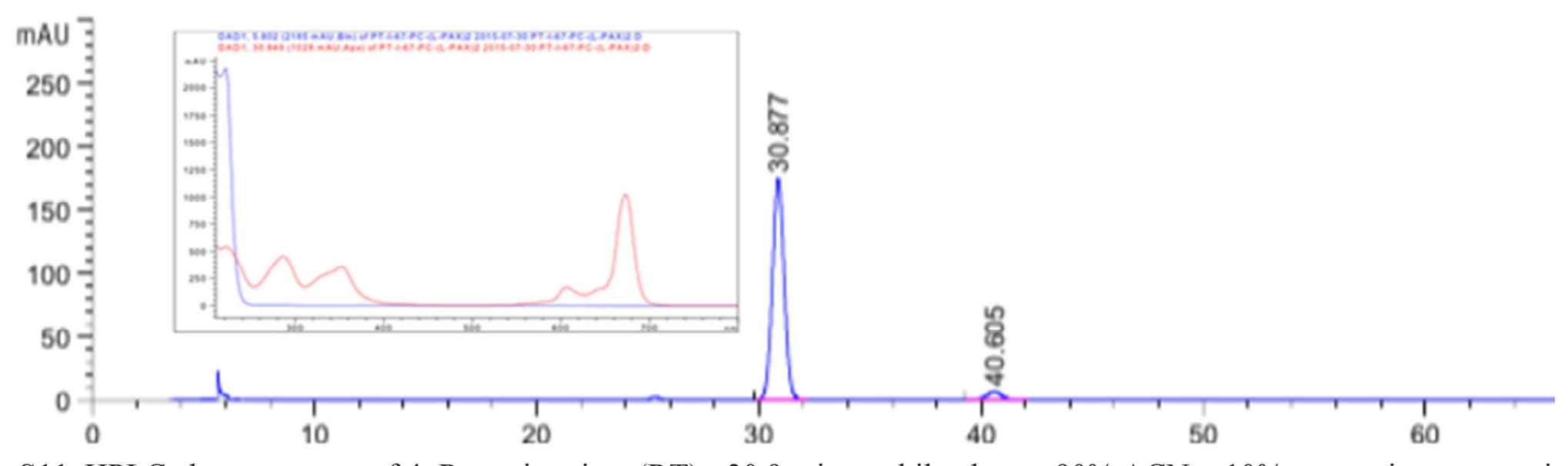

Figure S11. HPLC chromatogram of 4: Retention time (RT) - 30.9 min, mobile phase - 90\% $\mathrm{ACN}+10 \%$ ammonium acetate in $\mathrm{dH}_{2} \mathrm{O}$ $(10 \mathrm{mM})$ at a flow rate of $0.5 \mathrm{~mL} / \mathrm{min}$, Injection solvent - 5\% DMSO in ACN, Purity: 95\%.

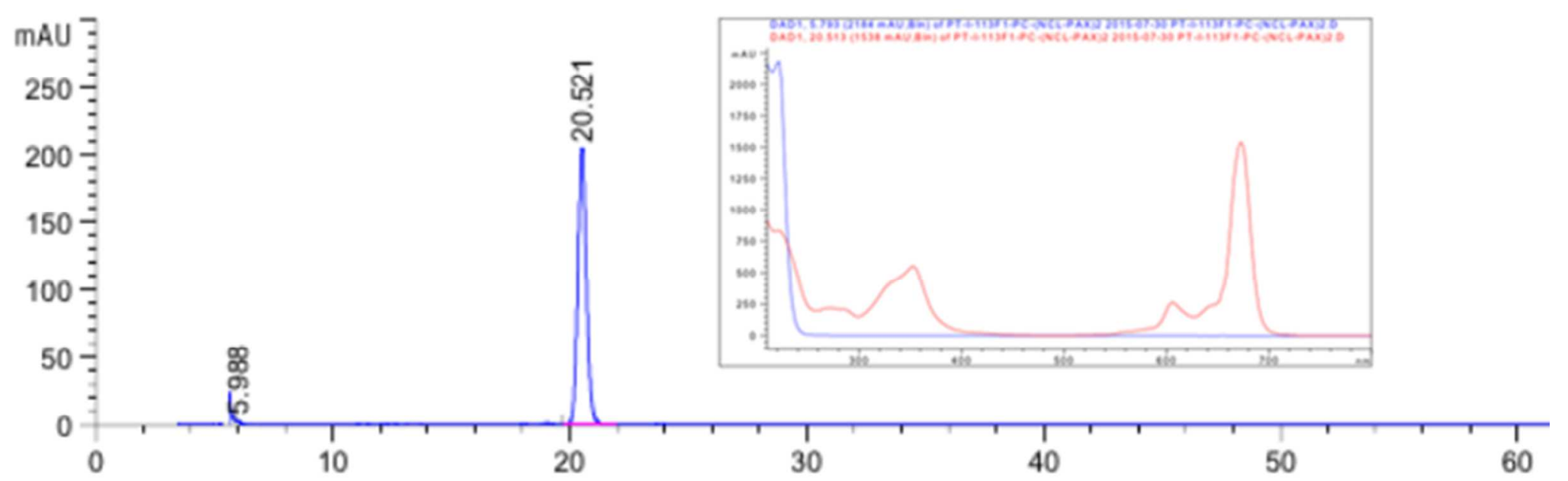

Figure S12. HPLC chromatogram of 5: Retention time (RT) - $20.5 \mathrm{~min}$, mobile phase $-90 \% \mathrm{ACN}+10 \%$ ammonium acetate in $\mathrm{dH}_{2} \mathrm{O}$ $(10 \mathrm{mM})$ at a flow rate of $0.5 \mathrm{~mL} / \mathrm{min}$, Injection solvent - 5\%DMSO in ACN, Purity: 98\%. 

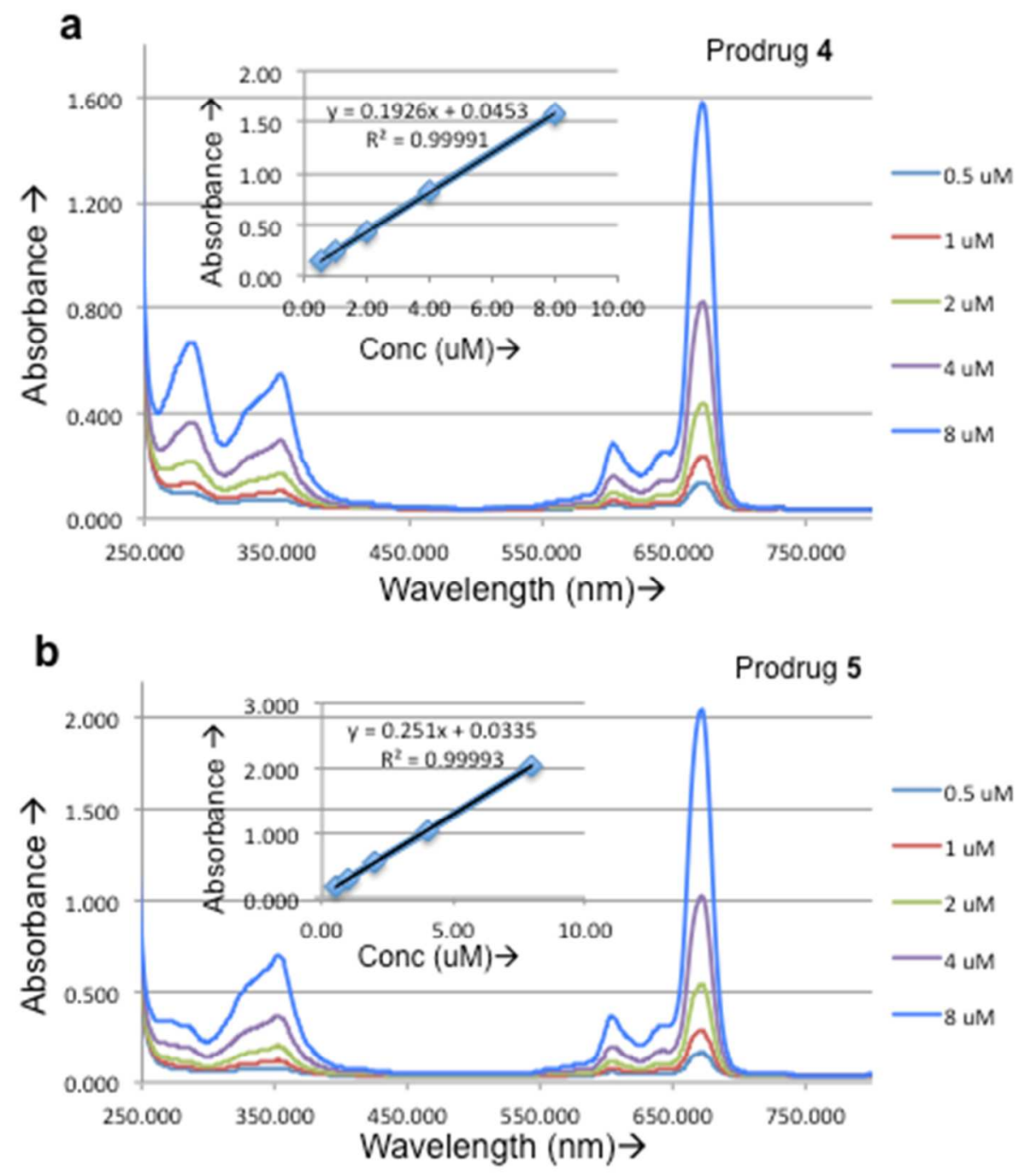

Figure S13. UV/Vis absorption spectra of (a) 4 and (b) 5 measured in 5\% DMSO in ACN. 


\section{Procedure for sample collection with HPLC from the illuminated solution of prodrug 4}

To confirm the identity of the released product from the illuminated solution of $\mathbf{4}$ as PTX, we collected the isolated peak (near $\sim 11$ min). HPLC was performed with isocratic mobile phase of $60 \% \mathrm{ACN}$ and $40 \% 10 \mathrm{mM}$ ammonium acetate in $\mathrm{dH}_{2} \mathrm{O}$ (milliQ). After

sample collection, ACN was removed using a nitrogen flush. The remaining aqueous layer was transferred into a centrifuge tube by washing with $5 \mathrm{~mL}$ DCM. It was then vortexed for $1 \mathrm{~min}$ and centrifuged at $3000 \mathrm{rpm}$ for 10 min. The upper aqueous layer was carefully removed using a Pasteur pipette and discarded. The remaining DCM layer was then concentrated and reconstituted with ACN. $10 \mu \mathrm{L}$ of sample was injected into HPLC to confirm the sample peak at 11 min (retention for standard PTX; Fig. S14). HRMS, which showed the mass peak of PTX, was taken for the sample (Fig. S14). 


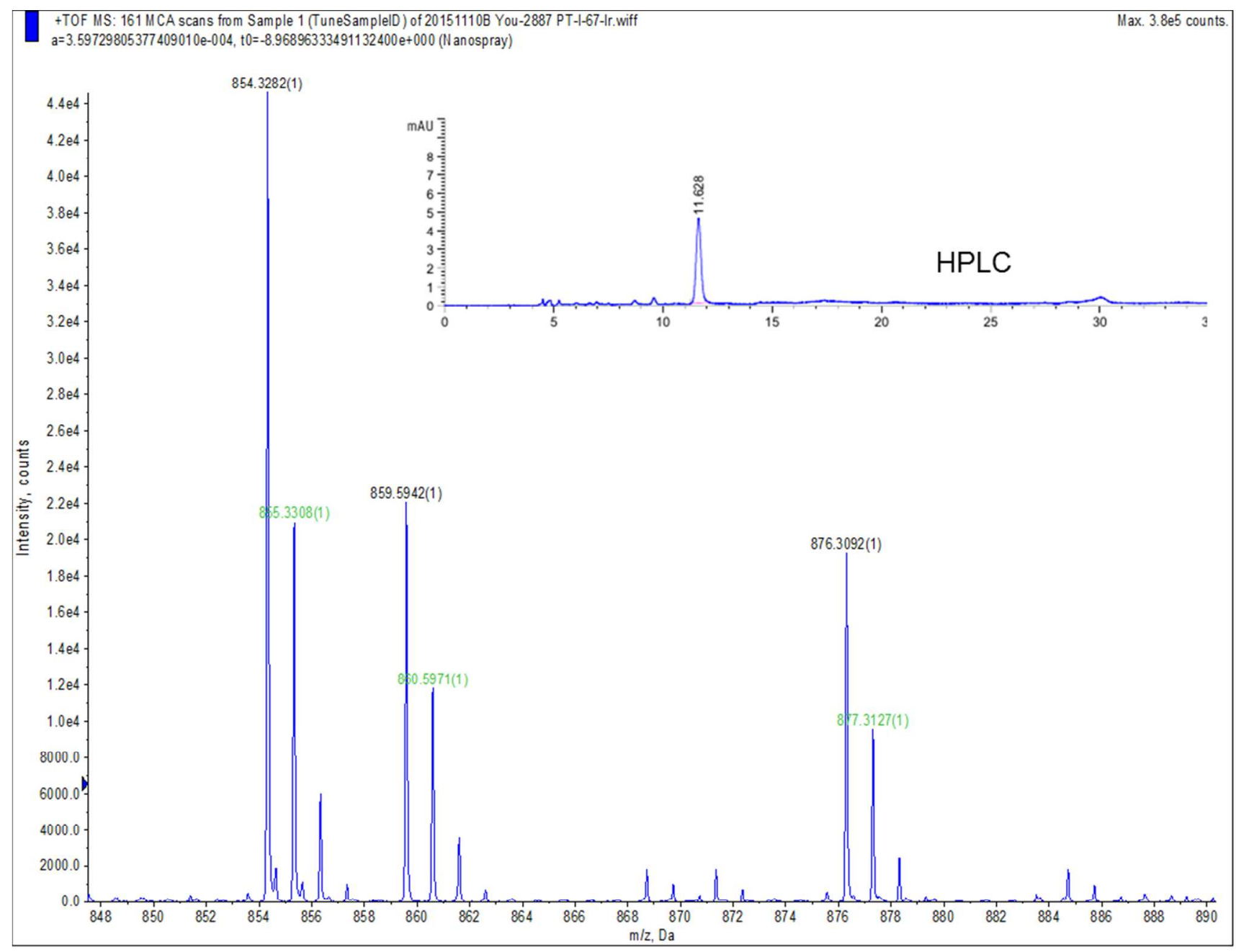

Figure S14. HPLC chromatogram and HRMS of the peak obtained from HPLC purification from the illuminated sample of 4. PTX: HRMS-ESI : $m / z$ calcd. for $\left[\mathrm{C}_{47} \mathrm{H}_{52} \mathrm{NO}_{14}\right]^{+}: 854.3388[\mathrm{M}+\mathrm{H}]^{+}$; found: $854.3282 ; \mathrm{m} / \mathrm{z}$ calcd. for $\left[\mathrm{C}_{47} \mathrm{H}_{51} \mathrm{NNaO}_{14}\right]^{+}: 876.3207[\mathrm{M}+\mathrm{Na}]^{+}$; found: 876.3092 . 


\section{Tubulin polymerization effects of illuminated samples of compounds 4 and 5}

To a 3-cm-diameter glass beaker, we added the solution of 4 or $5(0.5 \mathrm{~mL}, 30 \mu \mathrm{M})$ in complete medium, diluted from the DMSO stock solution. The beaker was illuminated from above with a laser $\left(690 \mathrm{~nm}, 5.6 \mathrm{~mW} / \mathrm{cm}^{2}\right)$ for $30 \mathrm{~min}$. After illumination, the sample was added to the tubulin mixture at a final concentration of $1.5 \mu \mathrm{M}$. The tubulin polymerization test procedures are described in the experimental section, Tubulin Polymerization Assay.

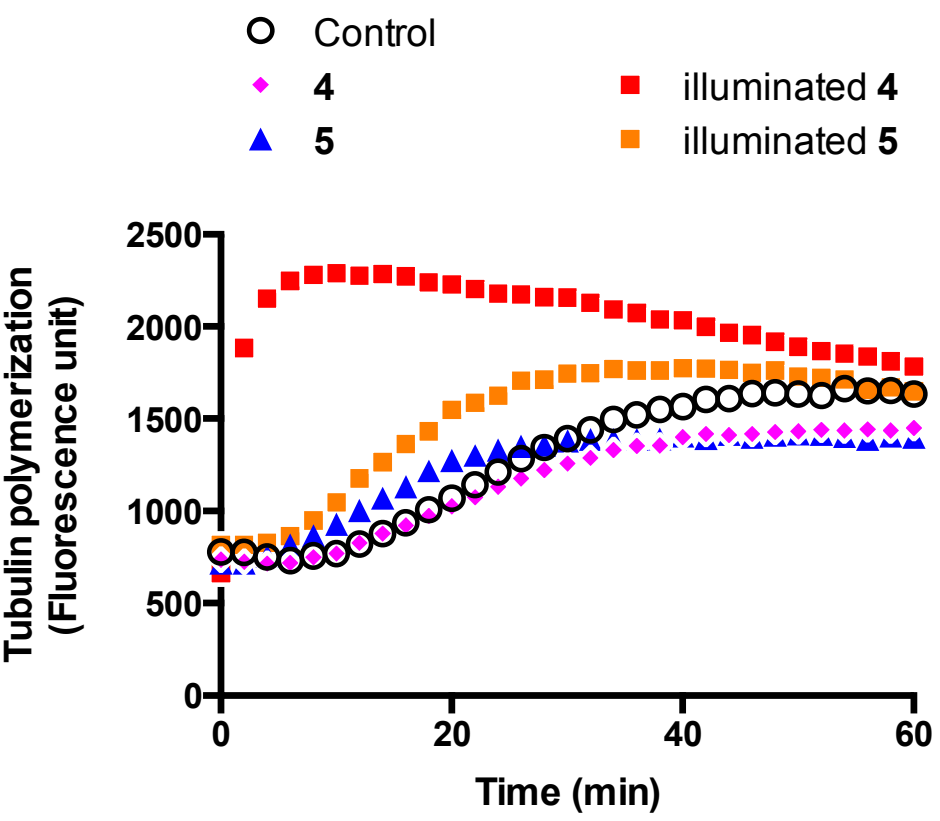

Figure S15. Effects of $\mathbf{4}$ or 5 on tubulin polymerization at a $1.5 \mu \mathrm{M}$ concentration, before and after illumination. 


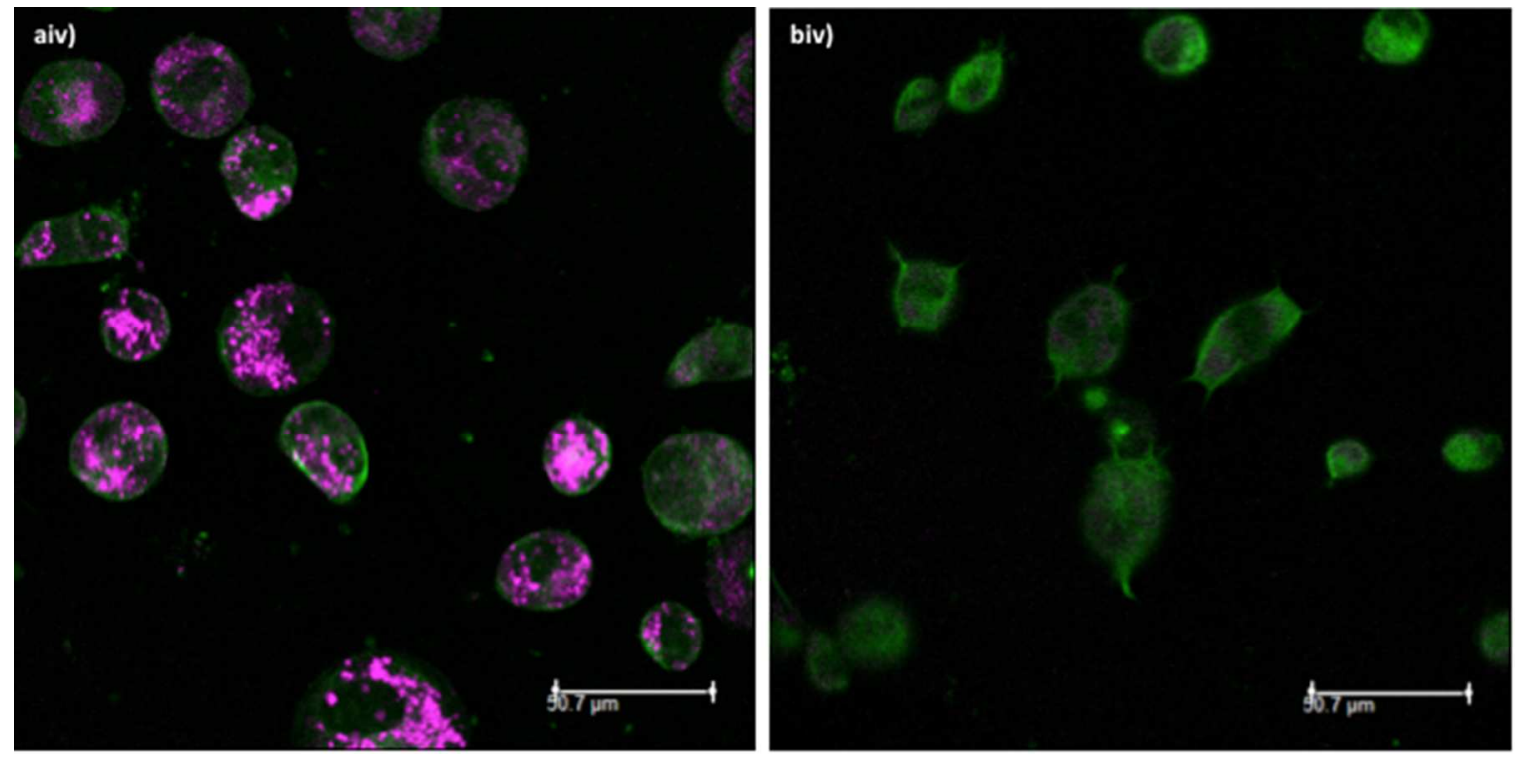

Figure S16. Enlarged images of Figures 6aiv and 6biv. 


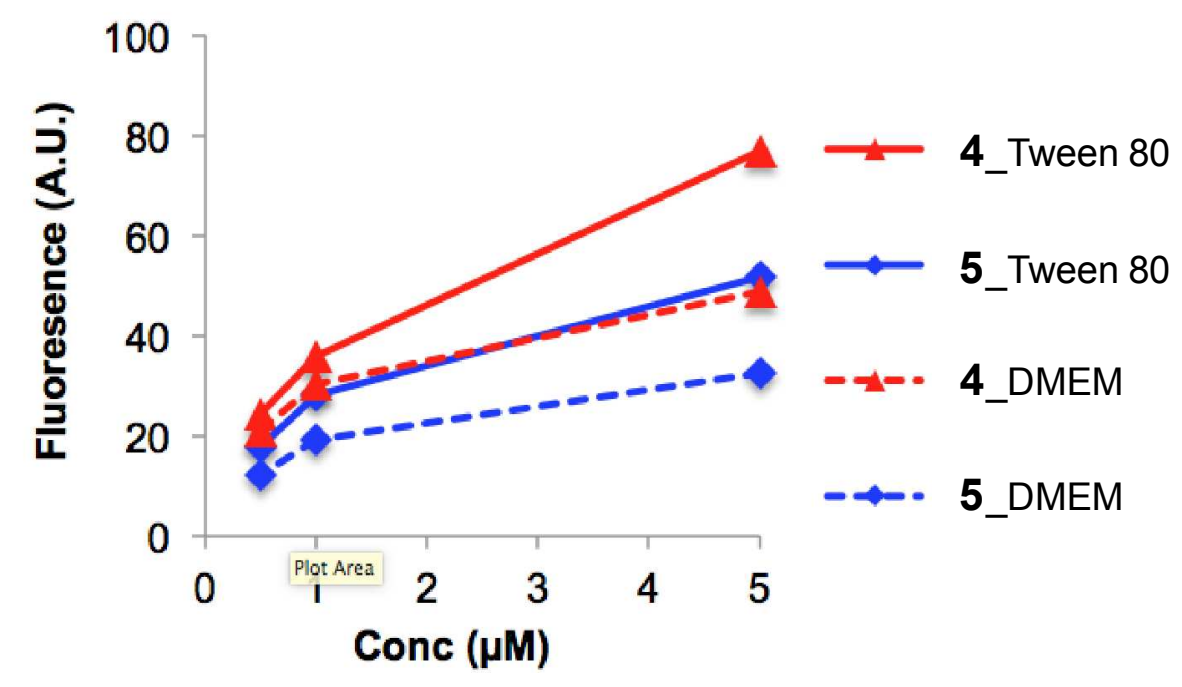

Figure S17. Relative fluorescence intensity of prodrugs 4 and 5 in DMEM media or Tween80 (1\%)/dextrose (5\%) after 24 h incubation at various concentrations. Fluorescence was measured in a black, clear bottom 96-well plate with excitation at $615 \mathrm{~nm}$ and emission at $680 \mathrm{~nm}$. 